\title{
Metaconvergence as a methodological strategy of education in information culture
}

\author{
Olga Andreeva ${ }^{1}$, and Artur Eldarion ${ }^{2 *}$ \\ ${ }^{1}$ Vladivostok State University of Economics and Service, 690014, Vladivostok, Russia \\ ${ }^{2}$ Pacific State Medical University, 690002, Vladivostok, Russia
}

\begin{abstract}
The aim of the study is to formulate a methodological education strategy that is adequate to the modern socio-cultural situation, which will allow, when using the achievements of digital technologies, to maintain the humanistic dimension of the student's consciousness. The scientific novelty of the research lies in the proposed methodological educational strategy - meta convergence. Metaconvergence is a way of realizing an educational co-being that initiates the reproduction of cultural matrices in the "sphere of one's own" subject of education. Metaconvergence, forming the ontological prerequisites of knowledge, makes it possible to organize pedagogical communication in a special way, which is capable of synthesizing educational, personal and cultural dimensions into a single tissue. The research methods were phenomenological and systemic approaches. The phenomenological method made it possible to structure the problem of the methodology of education in the context of the premiselessness, as well as to thematize education in terms of the ability to form meaning within the boundaries of the subject knowledge. The use of the procedures of the systemic method made it possible to build the realizable tasks of the educational process into a system, the core of which is the concept of metaconvergence as a methodological educational strategy. As a result the use of the declared methodological educational strategy, educational tasks of the humanitarian, communicative, motivational and axiological spectrum are solved. It is shown that meta convergence makes it possible to overcome the boundaries of disciplinary paradigms and to approve the need for a humanitarian attitude at an interdisciplinary level.
\end{abstract}

\section{Introduction}

The post-industrial era defines the modern way of life, which is closely related to the total digital mediatization of social spaces. Today digital technologies determine the culture of everyday life and the basic constituents of socio-cultural practices [1]. Education as a form of social communication is not exception.

Currently, we are witnessing discussions on the integration of digital technologies into the body of the educational system $[2,3,4]$. The polarity of positions on this issue ranges from violent jubilation in relation to the total digitization of the education system to harsh

\footnotetext{
* Corresponding author: arthorius.eldarion@gmail.com
} 
criticism of the integration of digital technologies into the education sector. Thus, the transformation of the educational process associated with the integration of digital technologies provokes the actualization of the problems associated with the revision of methodological issues that previously existed only on the periphery of pedagogical interest.

The grounds for the change in methodological priorities are rooted in the transformations that the modern cultural space has undergone. The product of the information age is the emergence of a new order of cultural communication. The turn to visual culture is characterized by the transition from the intelligible to the visually perceptible: the carrier of information, thanks to which modern communication functions, is the visual text. It is a structure in which the image is primary and the text is secondary. The new cultural matrix produces a "deconstruction" of consciousness, defining its visualcommunicative format.

Contemporary culture is called screen culture [5]. The screen is a part of the everyday life of a modern person, coordinating the individual consumption of screen images. The new interactive type of screen communication concerns not only the areas of television and the internet that are obviously related to the screen, but also other social practices. So, taking into account the specifics of the formation of social and individual consciousness, in which modern screen culture actively participates, there is a need to rethink the possibilities of applying modern educational strategies.

The thesis about the inevitable and necessary digitalization of education requires a critical understanding of the existing educational methodological foundations, awareness and formulation of problems, as well as the search for new, adequate ways to solve them. It must be admitted that information culture, characterized by richness and dynamism of content, to a greater extent provokes the question of not what to teach, but how to teach. Hence, the complexity, multidimensionality of the problem requires attention, detailed analysis and comprehension at the level of elaboration of the methodology of the educational process.

Thus, the purpose of the study is to formulate a methodological education strategy that is adequate to the modern socio-cultural situation, which will allow, when using the achievements of digital technologies, to maintain the humanistic dimension of the student's consciousness.

The problem of the information cultural space is universal, however, the content and development of the questions posed depend on the perspective of the problem. Modern research on the specifics of visual culture and its impact on various aspects of human life is a subject of discussion not only in the studies of philosophy, but cultural anthropology [6], psychology [7], sociology [8] and pedagogy [9].

So, in philosophical discourse, the issue of a visual turn in culture is interpreted as a turn "from the book to the screen" [10], "from the symbolic to the imaginary" [11]. Anthropological issues in the context of mass communications are raised by such philosophers as J. Baudrillard [12] and S. Zizek [13]. The nature of mass media communications is investigated by N. Luhmann [14]. S. Z. Hamrah, from an existential perspective, raises the question of the relationship between knowledge and experience in the modern educational process [15].

The specifics of the methodology and communications of the educational process in the context of digital culture are being actively developed within the framework of "digital pedagogy" [16], where researchers comprehend the issues of adaptation of traditional pedagogy to new technologies [17], as well as the boundaries and possibilities of digital education in society, in general [18]. The questions of the specifics of teaching the disciplines of the humanitarian cycle and conducting lectures in the context of digitalization of universities are raised [19]. Various aspects of the methodological problems of digital 
education in a modern university become the subject of research in the works of N. Selwyn [20], J. Dobson [21] and T. Fawns [22].

Despite a sufficient number of philosophical, cultural, psychological and other scientific studies devoted to the methodological problems of education in a digital culture, this topic cannot be called fully developed. Attempts to comprehend the problem are still fragmentary. It is necessary to overcome the methodological disunity of various disciplines, as well as to develop a categorical apparatus adequate to the modern educational space.

\section{Methodology and Methods}

Methodologically, the authors adhere to the main provisions of the phenomenological tradition of E. Husserl [23]. The phenomenological method made it possible to structure the problem of the methodology of education in the context of preconditions, as well as to thematize education in terms of the ability to form meaning within the boundaries of the subject knowledge.

In the process of research, a systematic approach is applied, within which the elements of the educational process are built into a system of educational strategy, the core of which is the metaconvergence methodology. In addition to the listed methods, the axiological approach, as well as the structural method and comparative analysis, were used to achieve the research aim.

\section{Results}

The metaconvergence methodology presupposes the creation of conditions for the implementation of such communication, where, on the one hand, interdisciplinarity, project-based education is possible, in which traditional methods are implemented in a new digital format, and, on the other hand, there is a retention in the unity of educational, personal and cultural dimensions. Thus, metaconvergence refers us to the ontologically rooted structures of education, which make it possible to organize pedagogical communication in such a way that the opportunity to solve the problems of the humanitarian, axiological, communicative and motivational spectrum is realized. In the study, the authors formulated the problem areas of the designated tasks.

The humanitarian task is associated with the need to bring knowledge into the space of the individual: knowledge must become personally significant, possess an anthropological dimension. Here, first of all, attention is focused on what conditions allow the student to psychologically experience the acquired knowledge as personally significant and, in this sense, his own. The humanistic aspect is associated with the comprehension of the disciplinary boundaries that have developed in pedagogical thinking and overcoming the idea of educational as a uniform system of formal didact. The transformation of the student's status seems to be relevant: from an object to a subject of the educational process.

The communicative task is associated with the search for such educational strategies that are able to create around themselves the necessary communicative field that ensures the convergence of consciousness. The high dynamics of modern culture provokes the problematic nature of not only identity, but also the possibility of dialogue between generations. Hence, the restoration of the social fabric of interaction as a space of dialogue is becoming an urgent issue of modern liberal arts education. The mechanics of postmodern screened culture give rise to narcissistic media-autistic people who neutralize the figure of the Other. One of the leading tasks of the educational process is the creation of conditions for communication, in which openness is provoked and the restoration of the lost connections between the participants of pedagogical communication will be realized. The 
rapprochement of initially dissimilar consciousnesses of the student and the teacher is productively realized exclusively as an opportunity for communicative co-existence. A prerequisite for creating a communicative co-existence is the teacher's possession of certain methods of pedagogical activity, in which a moment of understanding is possible as mutual understanding between participants in a communicative situation.

The axiological task is associated with the need to form value orientations. The current ethical principle of tolerance presupposes a refusal to assert the uniqueness and universality of a certain moral system. For the emerging personality, the problematic task is to maintain a certain balance between different moral systems, due to the lack of understanding on what philosophical grounds this or that position was built. To prevent the absurd situations that modern man faces in terms of ethics, it is necessary to comprehend the discourse of tolerance in the context of educational situations. Pedagogical strategies should include provoking an understanding of the ethical foundations of human life, so that moral imperatives are not uncritically accepted norms from the outside.

The motivational task of educational activity is associated with the satiety of the modern information space. The availability of information reduces the motivation for education, levels the authority of the teacher. And here the teacher needs to actualize the ancient archetype of the actor and the seducer: he must "tempt" the student with education. To provoke education is to induce mental activity. This is a teaching method in which the student himself actively participates in the educational process, in which knowledge is not communicated as postulates and ready-made truths. The student, together with the teacher, participates in the discovery of knowledge for himself. Thus, the knowledge discovered by the student himself becomes his own knowledge, and therefore more valuable and understandable. Provocative educational techniques are just needed to destroy the logic of everyday thinking while simultaneously forming the meaningfulness of the knowledge acquired and preserving the student's motivational basis.

An important point is the active participation of the teacher's personality and included person as well, real communication, meetings "face to face". In this case, the driving force should be the dialogue, which forms the basis of creative pedagogy. A "hologram" of a teacher, even made at a high-tech level and with the use of advanced technologies, will not replace the live experience of a meeting. Methodological techniques in modern education should contribute not to the creation of an accessible system of knowledge, but to the formation of conditions for the possibility of actualizing understanding and knowledge as one's own. This landmark can be considered a necessary and significant goal of modern education, since in such conditions it is possible to actualize the meaningfulness and creativity of the student, within the boundaries of which the subject of the educational process is formed as a person.

\section{Discussion}

The authors of this study started from the theory of convergence, where convergence means the process of convergence and synergistic interaction of dissimilar features [24]. In the context of educational methodology, convergence is viewed as a special kind of communicative interaction of heterogeneous minds of participants in the educational process. Convergent communication presupposes non-fusion, inseparability of original personal worlds [25]. Convergent interaction is focused on convergence, not fusion, on the consistent bringing of the developing consciousness to unity with other equally original consciousness of the teacher. Such a meeting of consciousnesses helps to overcome the fragmentation of pedagogical interaction and ensures the integrity of the educational, personal and cultural dimensions. 
Metaconvergence, on the other hand, allows us to move further in the philosophical understanding of methodological problems, since this concept refers us to the ontological order of the educational process, within which the conditions for the meeting of consciousnesses in a single field of communicative interaction are fulfilled.

This methodological strategy is successfully implemented, especially for the disciplines of the humanities, in particular, philosophy. Since it is precisely in teaching the humanities that a formal postulation of truths without problematization, comprehension and reflection leads away from what should be called education today. After all, it is precisely the nature of humanitarian knowledge, as the Soviet philosopher M.K. Mamardashvili, the essence of the "humanitarian spark", is directly related to the spiritual development of the individual and the ability to comprehend the knowledge gained. Isn't that what should be called the goal of education today in the first place?

Thus, in the educational process, it is legitimate and justified to update such educational strategies that include a problem, organize a discussion, cause feelings and, as a result, contribute to the convergence of consciousness at the level of all participants in the educational process. However, such a rapprochement cannot take place within the framework of the traditional pedagogy of formal didact, since the participants in the educational process must be on an equal footing, being full-fledged participants in the educational co-being in order to implement the principle of reciprocity.

This methodological strategy has been applied at all times: the conversations of the ancient Greek philosopher Socrates, the loving pedagogy of Jesus Christ suggested a similar attitude. The modern and relevant methodology of the educational process should act as a favorable condition for the productive implementation of the proposed educational strategies and allow the implementation of already known pedagogical techniques in modern realities. In this context, digital technologies should act as effective intermediaries between the initially different minds of the teacher and the student.

\section{Conclusions}

Mass media communications, being a part of the social space, provokes questions to academic education: how to fit the variability of socio-cultural processes into the formation of a student's integral worldview, while maintaining the anthropological dimension of knowledge? The teacher's methodological strategy and his methodological techniques are becoming important, which will make it possible to maintain the humanistic component of the educational process in the context of the dynamism and media nature of the cultural space. The development and implementation of digital communication technologies in all spheres of socio-cultural life confronts education with a new solution to the problems of the humanitarian, axiological, communicative and motivational spectrum.

Metaconvergence as a methodological strategy of education substantiates the humanitarian context of knowledge in a dynamic cultural media space. Metaconvergence as an educational practice is based on the creation of conditions for the implementation of such pedagogical interaction, in which traditional methods, implemented in a new digital format, do not lead to the loss of the humanistic and motivational context. In this case, the student appears not as a consumer of ready-made information, but as an active participant in the educational process. In this case, it acts not just as an object of pedagogical manipulations, which is involved in communication processes against its own will, but becomes an author, a co-participant of the educational process, which uses the developments of digital culture as additional means of creative self-realization.

The direction of further research is determined by the ambiguity in the interpretation of the meaning of the visual turn in the field of education, as well as by the lack of development of ontological and methodological aspects of education. One of the possible, 
today, lines of development of the discussed problem lies in the field of phenomenology of education, which in turn does not correlate with a simple methodology at the level of a teacher's work, but is associated with the process of comprehending the conditions of educational strategies at the level of philosophical discourse.

\section{References}

1. J.P. Marshall, An Interdisciplinary Journal 2 (9), 1-24 (2017). DOI: 10.5130/ccs.v9i2.5477

2. N. Mercer, S. Hennessy, P. Warwick, International Journal of Educational Research 97, 187-199 (2019). DOI: 10.1016/j.ijer.2017.08.007

3. M. Dado, D. Bodemer, Educational Research Review 22, 159-180 (2017). DOI: 10.1016/j.edurev.2017.08.005

4. N.C. Jackson, Business Horizons 6 (62), 761-772 (2019). DOI: 10.1016/j.bushor.2019.08.002

5. G.L. Tulchinsky, The Art and Science of Television 2 (15) 29-40 (2019). DOI: 10.30628/1994-9529-2019-15.2-29-40

6. H. Jenkins, Confronting the challenges of participatory culture: media education for the 21 st century, The MIT Press, Cambridge (2009).

7. I. Granic, A. Lobel, R.C. Engels, American Psychologist 1 (96), 66-78 (2014). DOI: 10.1037/a0034857

8. L. Hietajärvi, K. Salmela-Aro, H. Tuominen, K. Hakkarainen, K. Lonka, Computers in Human Behavior 93, 13-24 (2019). DOI: 10.1016/j.chb.2018.11.049

9. C. Young, J. Reid, B. Meehan, Current Opinion in Environmental Sustainability 16, 64-72 (2015). DOI: 10.1016/j.cosust.2015.07.002

10. G. Agamben, The fire and the tale (Stanford University Press, Stanford, 2017).

11. L.I. Kirsanova, O.A. Korotina, Gênero\&Direito 4 (9) 1072-1091 (2020). https://periodicos.ufpb.br/index.php/ged/article/view/53184, last accessed 2021/02/23

12. J. Baudrillard, Telemorphosis. Univocal, Minneapolis (2011).

13. S. Zizek, Like a thief in broad daylight: power in the era of post-humanity (Allen Lane, London, 2018).

14. N. Luhmann, Theory of society (Stanford University Press, Stanford, 2012).

15. S.Z. Hamrah, Procedia - Social and Behavioral Sciences 29, 1750-1758 (2011). DOI: 10.1016/j.sbspro.2011.11.421

16. D. Lewin, D. Lundie, Studies in Philosophy and Education 35, 235-240 (2016). DOI: 10.1007/s11217-016-9514-7

17. L. Marin, J. Masschelein, M. Simons, Educational Philosophy and Theory 1 (50), 4960 (2018). DOI: 10.1080/00131857.2017.1323624

18. T. Dufva, M. Dufva, Futures 107, 17-28 (2019). DOI: 10.1016/j.futures.2018.11.001

19. L. Marin, Hodgson, N., Vlieghe, J., Zamojski, P. (eds.), Debating Higher Education: Philosophical Perspectives 3, 73-82 (2020). DOI: 10.1007/978-3-030-45019-9_6

20. N. Selwyn, Digital technology and the contemporary university, 1st ed. Routledge, London (2014).

21. J.E. Dobson, Critical digital humanities: the search for a methodology (The University of Illinois Press, Urban-Champaign, 2019). 
22. T. Fawns, Postdigital Science and Education 1 (1), 132-145 (2019). DOI: 10.1007/s42438-018-0021-8

23. E. Husserl, Ideas: general introduction to pure phenomenology (Routledge, London, 2012).

24. Yu.P. Zinchenko, E.M. Dorozhkin, E.F. Zeer, The Education and Science Journal 3 (22), 11-35 (2020). DOI: 10.17853/1994-5639-2020-3-11-35

25. V.I. Tyupa, Bulletin of the Herzen University 1, 56-66 (2012). 